\title{
Tackling covid-19: are the costs worth the benefits?
}

\author{
Too much uncertainty remains for evidence based decisions, says John Appleby
}

\author{
John Appleby director of research and chief economist
}

Nuffield Trust, London, UK

It is hard to write about the economics of covid-19 while we are grappling with such an unprecedented global emergency. But questions are being voiced-from presidents and commentators to health economists ${ }^{1-3}$ and the German Council of Economic Experts ${ }^{4}$ - about the cost effectiveness of the measures being used to tackle the disease. In short: are the costs worth the benefits?

This may seem an outrageous question. Surely, we must do all we can to minimise mortality and morbidity from covid-19? But the cost-benefit question is one that all health systems face every day-is drug X better than drug Y (or doing nothing)? Should stroke services be centralised? How long should treatment continue for a particular patient? Or more specifically, which patients with covid-19 should be prioritised for ventilation ${ }^{5}$

Although there is no simple fix to many of these wicked choices, the National Institute for Health and Care Excellence (NICE) was set up in the UK in an attempt to make what were previously somewhat opaque decisions more transparent and more consistent. The weighing up of costs and effects to be judged against a threshold value of the effects (benefits) is at the heart of NICE's decision making.

As UCL academics Shepley Orr and Jonathan Wolff point out, cost effectiveness may be characterised as a somewhat heartless utilitarian approach, but it actually has a concern for fairness in the use of scare resources ${ }^{6}$; a concern with the opportunity cost or lost benefits (economic and health) of a decision to do $\mathrm{X}$ for the benefit of one group of people instead of $\mathrm{Y}$ for another group.

But, as Orr and Wolff also note, it can be hard to reconcile the outcome of a cost effectiveness analysis that suggests an intervention is not worth doing when it comes to certain situations, such as rescuing people in emergency situations. So does cost effectiveness even have a role when it comes to covid-19-undeniably an emergency?

There is still considerable uncertainty about the impact of the pandemic. Up to 19 April reported cases of covid-19 in the UK totalled 120067 , and the number of deaths in hospital was 16
060 (figs 1 and 2). A proportion of those who have so far died with covid-19 would have died this year from other causes. Modelled estimates of the number of lives that could be lost in a "do nothing" situation suggested that there could be up to half a million deaths attributable to covid-19 over two years. ${ }^{7}$ To put this in context, the total number of deaths in the UK in 2018 was $616000 .^{8}$ These estimates also suggested that with a combination of non-pharmaceutical interventions-school closure, self-isolation, complete lockdown, social distancing, and banning of public events-plus treatment, deaths from covid-19 could be reduced to $250000 .^{7}$ Naturally, such figures represent best estimates so far and will change as the pandemic evolves.

More recent modelling suggests that by 31 March the interventions in place in the UK (introduced from 12 March to 24 March) had saved around 370 lives compared with a model of no interventions (which estimated total deaths of 1800; fig 3). ${ }^{9}$ For Italy, further along the course of the pandemic, it is estimated that by the end of March around 38000 lives had been saved (out of a counterfactual of 52000 ) by the interventions put in place around 10 March. There are, and will be, therefore, undoubted benefits from the interventions the UK has been pursuing to mitigate the impact of covid-19- to "flatten the curve."

\section{Opportunity costs}

At this point the ugly question that could be asked is whether the value of the benefits (deaths averted or quality of life years (QALYs) saved, say) is more or less than the (opportunity) costs of the interventions. The costs will be measured in economic as well as health and healthcare terms. Opportunity costs will also include mortality and morbidity from conditions other than covid- 19 because of reduced use of health services and delays in treatment of other illnesses arising from the NHS prioritising resources on covid-19. Some indication of these from the Office for National Statistic's regular monitoring suggests that for the week ending 3 April for England and Wales, there were 3475 deaths from covid-19 but 6082 more deaths from all causes compared with the five year average for this week..$^{10}$ It remains 
to be seen how many of the "excess" non-covid deaths could be the result of covid-19 interventions and changes in the public's healthcare seeking behaviour.

Despite some early estimates from the US suggesting that there is a net benefit of social distancing and isolation versus the hit on the economy, ${ }^{112}$ these estimates come with large uncertainty. Of course, the cost-benefit balance could change depending on the success of all the interventions being tried, including possibly millions of extra tests, increased personal protective equipment, ventilators, etc-and, not least, the discovery of an effective vaccine. But for now, the nature of the covid-19 pandemic suggests we shouldn't base any decisions about doing something versus doing nothing on the results of inevitably imperfect and premature analysis of the costs and benefits.

Competing interests: We have read and understood BMJ policy on declaration of interests and have no relevant interests to declare.

Provenance and peer review: Commissioned; externally peer reviewed.

1 Trump D. "We can't let cure be worse than problem." 2020. https://www.bing.com/videos/ search?q=we+can\% $27 t+$ let+cure+be+worse+than+problem+itself+trump\& docid $=13822810068234 \&$ mid $=945270307$ A427EDOB 184945270307 A427ED0B184\& view=detail\&FORM $=$ VIRE

2 Young T. Has the government overreacted to the coronavirus crisis? The Critic $2020 \mathrm{Ma}$ 31. https://thecritic.co.uk/has-the-government-over-reacted-to-the-coronavirus-crisis/

3 van den Broek-Altenburg E, Atherly A. Economic cost of flattening the curve. Incidental Economist 2020 Mar 24. https://theincidentaleconomist.com/wordpress/economic-costof-flattening-the-curve/
4 German Council of Economic Experts. Special report 2020: The economic outlook in the coronavirus pandemic. https:/www.sachverstaendigenrat-wirtschaft.de/en/special-report2020.html?returnUrl=\%2Fen.html\&cHash=3b29536db7246d97e1 aac4902ee5beaf

5 Wynants L, Van Calster B, Bonten MMJ, etal . Prediction models for diagnosis and prognosis of covid-19 infection: systematic review and critical appraisal. BMJ 2020;369:m1328. 10.1136/bmj.m1328 32265220

6 Orr S, Wolff J. Reconciling cost-effectiveness with the rule of rescue: the institutiona division of moral labour. Theory Dec 2014; 10.1007/s11238-014-9434-3https://discovery. ucl.ac.uk/id/eprint/1358337/1/Orr_Wolff_Reconciling.pdf

7 Imperial College Covid-19 Response Team. Impact of non-pharmaceutical interventions (NPIs) to reduce COVID19 mortality and healthcare demand. Report 9. 2020. https://www. imperial.ac.uk/media/imperial-college/medicine/sph/ide/gida-fellowships/Imperial-CollegeCOVID19-NPI-modelling-16-03-2020.pdf

8 ONS. Vital statistics in the UK: births, deaths and marriages. 2019. https://www.ons.gov. uk/peoplepopulationandcommunity/populationandmigration/populationestimates/datasets/ vitalstatisticspopulationandhealthreferencetables

9 Imperial College Covid-19 Response Team. Estimating the number of infections and the impact of nonpharmaceutical interventions on COVID-19 in 11 European countries. Report 13. 2020. https://www.imperial.ac.uk/media/imperial-college/medicine/sph/ide/gidafellowships/Imperial-College-COVID19-Europe-estimates-and-NPI-impact-30-03-2020. pdf

10 ONS. Deaths registered weekly in England and Wales, provisional: week ending 3 April 2020. https://www.ons.gov.uk/peoplepopulationandcommunity/birthsdeathsandmarriages/ deaths/bulletins/deathsregisteredweeklyinenglandandwalesprovisional/latest

11 Thunström L, Newbold S, Finnoff D, Ashworth M, Shogren JF. The benefits and costs of flattening the curve for COVID-19. Journal of Cost Benefit Analysis 2020 [Epub ahead of print.] 10.2139/ssrn.3561934

12 Eichenbaum M, Rebelo S, Trabandt M. The macroeconomics of pandemics. Working paper 26882. National Bureau of Economic Research, 2020. https://www.nber.org/papers/ w26882

13 HM Government. COVID-19: track coronavirus cases. 2 April 2020. https://www.gov.uk government/publications/covid-19-track-coronavirus-cases

Published by the BMJ Publishing Group Limited. For permission to use (where not already granted under a licence) please go to http://group.bmj.com/group/rights-licensing/ permissions 


\section{Figures}

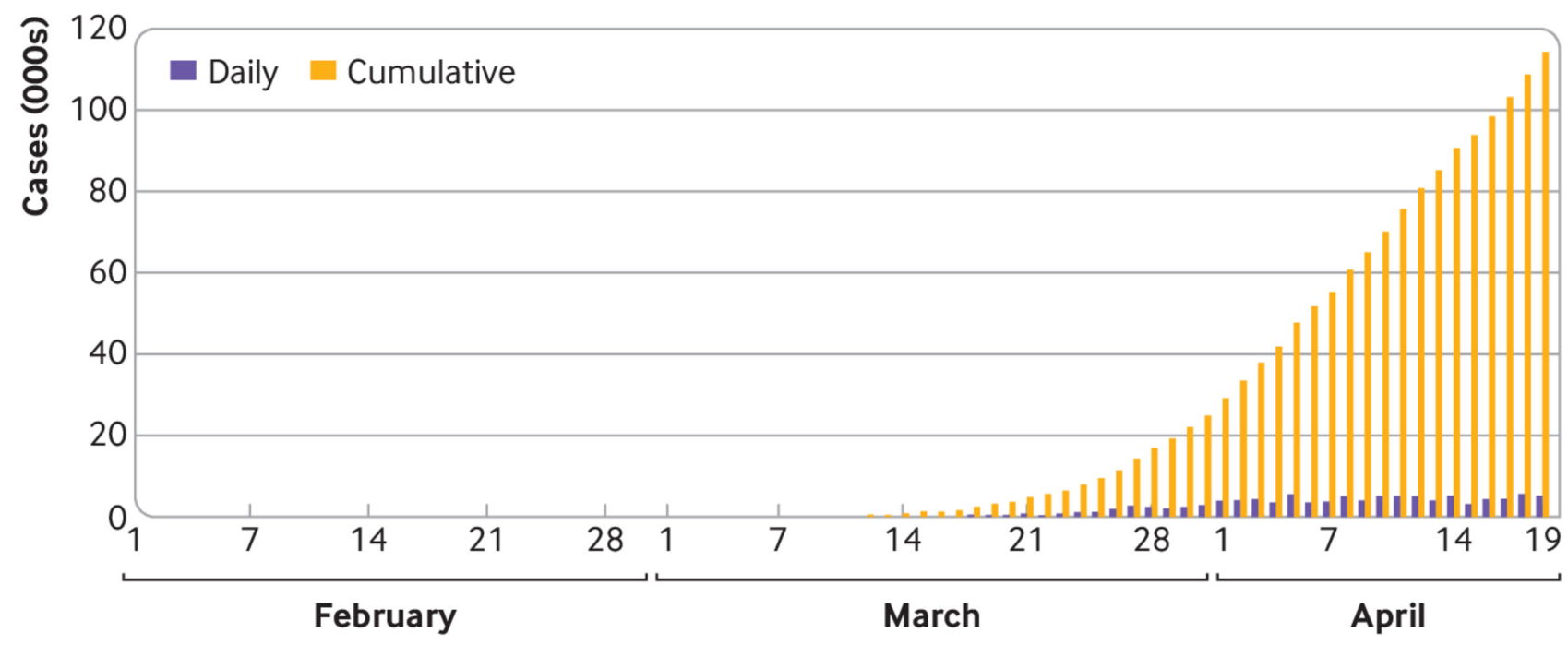

Fig 1 Confirmed cases of covid-19 in: UK up to 19 April $2020^{13}$

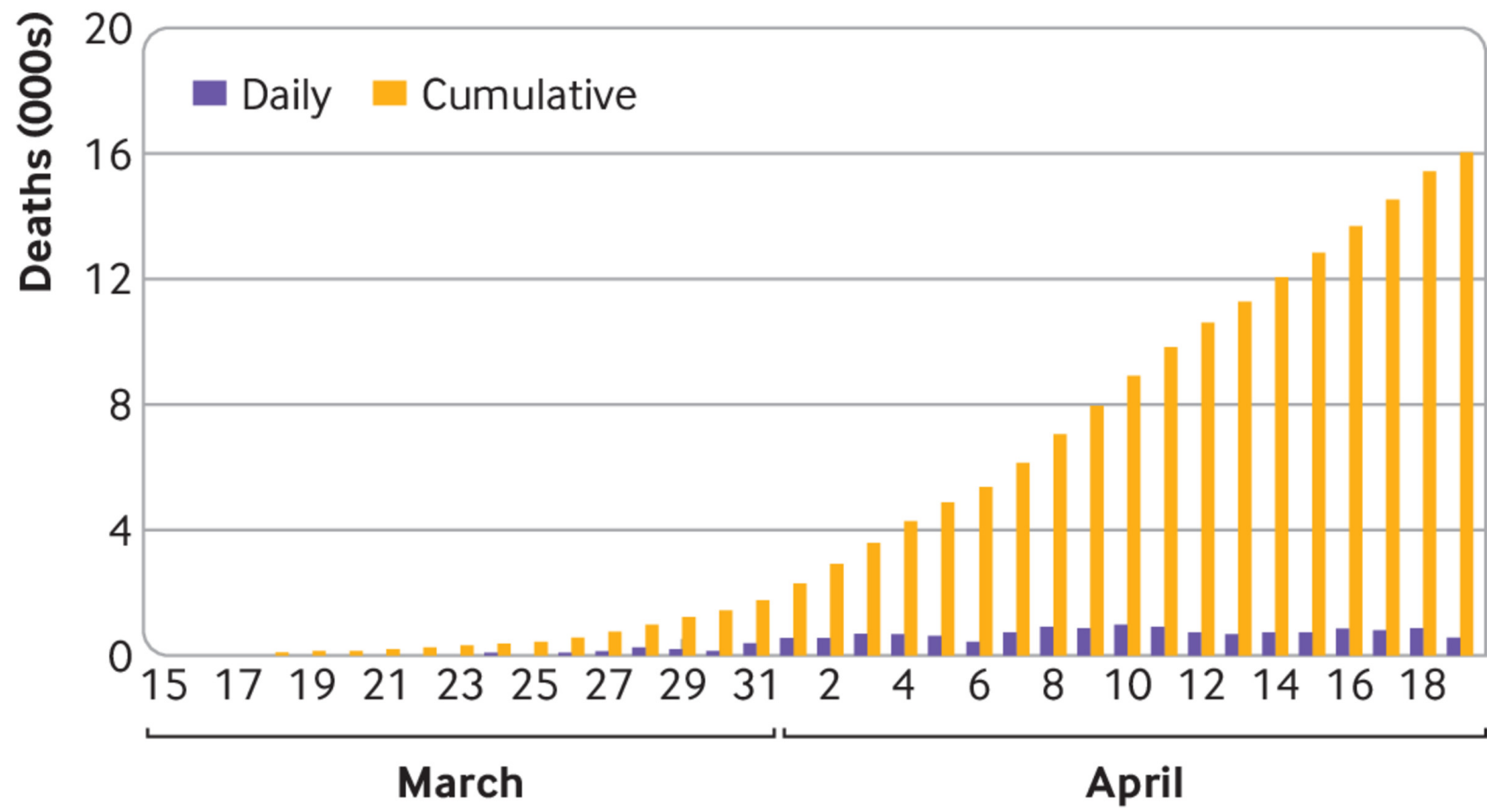

Fig 2 Deaths from covid-19 recorded in UK hospitals up to 19 April $2020^{13}$ 


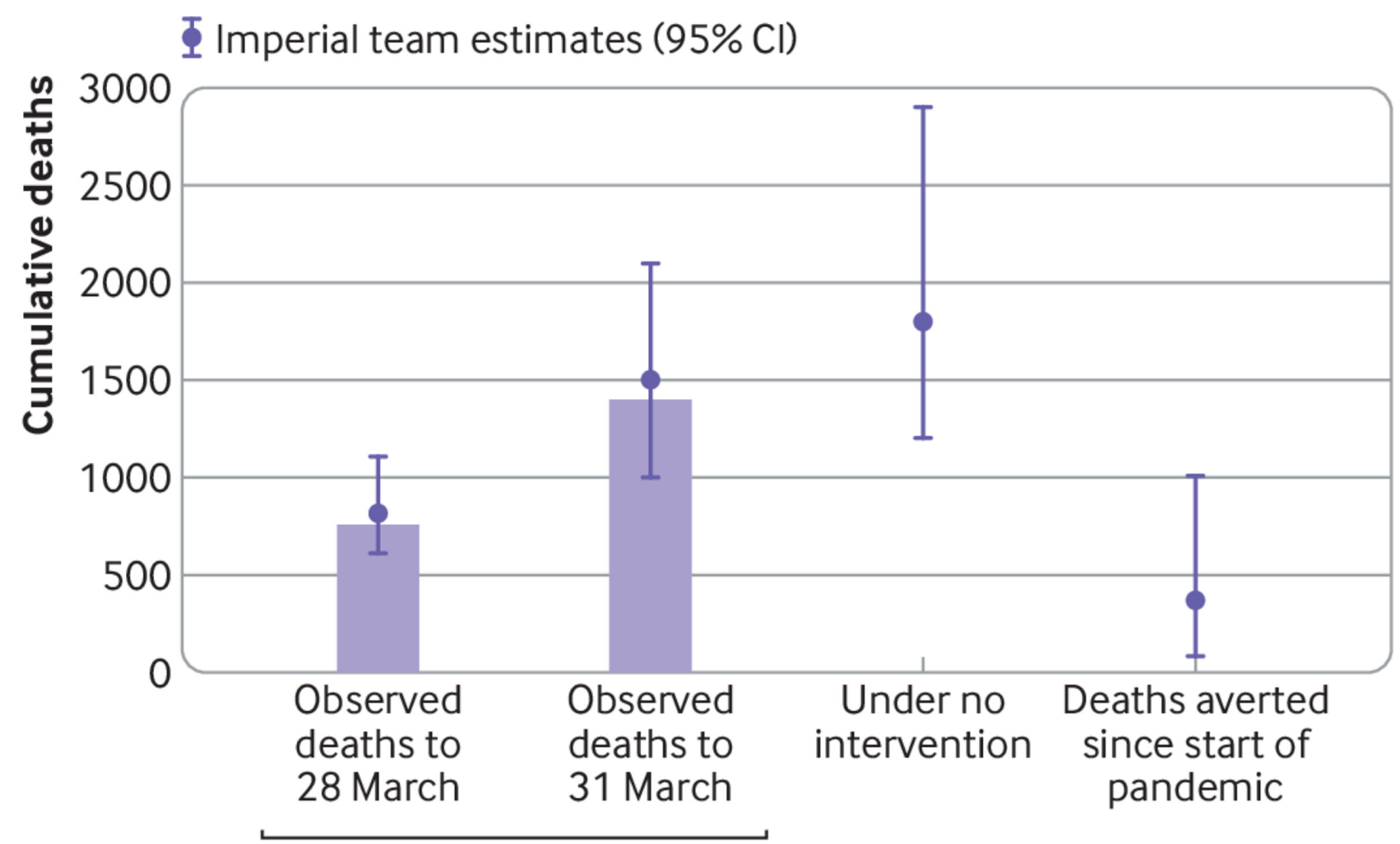

\section{Under current interventions}

Fig 3 Estimates of UK deaths from covid-19 deaths with and without non-pharmaceutical interventions compared with observed numbers using Imperial College modelling ${ }^{13}$ 